\title{
Direct Incorporation of Orally Administered Riboflavin Tetranicotinate into Portal Blood of Rabbit
}

\author{
Hiroshi OHKawa, Akira Kotaki AND Kunio Yagi ${ }^{2}$ \\ Institute of Biochemistry, Faculty of Medicine, \\ University of Nagoya, Nagoya (Post No. 466)
}

(Received March 10, 1969)

From the pharmacological interest of fat-soluble riboflavin derivatives such as $\mathrm{B}_{2}$ But (1) and $\mathrm{B}_{2}-\mathrm{Nic}$ (2), it is important to show whether these compounds are, when administered orally, incorporated through gastrointestinal tract into blood stream of mammals without losing their intactness of the ester bonds at $2^{\prime}, 3^{\prime}, 4^{\prime}$ and $5^{\prime}$ position. To test this, $\mathrm{B}_{2}-\mathrm{Nic}$ may be suitable because it is fairly soluble in water despite its considerable lipophilic nature, and is less susceptible to pancreatic lipase action than $\mathrm{B}_{2}$-But (3). In the present paper, evidence for the gastro-intestinal absorption of $\mathrm{B}_{2}$-Nic is briefly described.

Male rabbit weighing about $3 \mathrm{~kg}$ was administered orally with $500 \mathrm{mg}$ per $\mathrm{kg}$ body weight of $\mathrm{B}_{2}-\mathrm{Nic}$ which was dissolved in a fixed volume of $0.5 \mathrm{~N} \mathrm{HCl}$. As a control run, another rabbit was administered with the same volume of the solvent. At 2 hours after the oral administration, rabbits were anesthesized with urethane, and heparin was introduced into blood stream from their ear vein.

Then, $10 \mathrm{ml}$ of blood was collected from the portal vein of each rabbit and mixed with $40 \mathrm{ml}$ of a mixture of $1 \mathrm{~N} \mathrm{HCl}-\mathrm{CH}_{3} \mathrm{COONa}$ buffer $(\mathrm{pH} 2)$ and methanol $(3: 1, \mathrm{v} / \mathrm{v})$ with

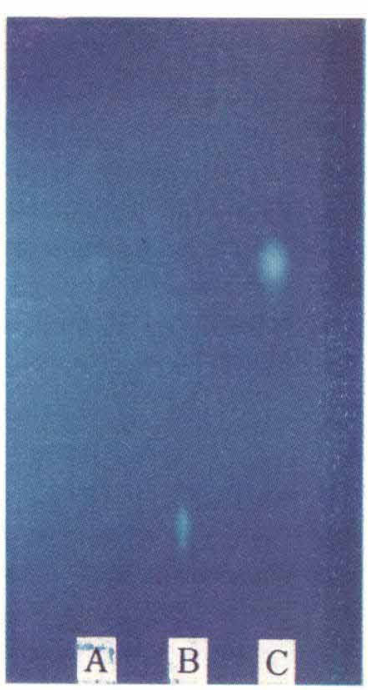

FIG. 1 TLC pattern of the phenol extract of portal blood from rabbit administered orally with $500 \mathrm{mg}$ of $\mathrm{B}_{2}$-Nic per $\mathrm{kg}$ of body weight

A : The extract, B : riboflavin, C : $\mathrm{B}_{2}$-Nic. TLC plates were prepared by coating a slurry of a mixture of silica gel and alumina $(1: 2, \mathrm{w} / \mathrm{w})$ and by activating at $120^{\circ}$ for 2 hours. As a developer, $\mathrm{CHCl}_{3}$-methanolacetic acid $(80: 20: 1, \mathrm{v} / \mathrm{v} / \mathrm{v})$ was used.

${ }^{1}$ Following abbreviations were used: $\mathrm{B}_{2}$-But, riboflavin $2^{\prime}, 3^{\prime}, 4^{\prime}, 5^{\prime}$-tetrabutyrate; $\mathrm{B}_{2}$-Nic, riboflavin $2^{\prime}, 3^{\prime} 4^{\prime} 5^{\prime}$ tetranicotinate; TLC, thin layer chromatography.

${ }^{2}$ 大川 博, 小滝 祥, 八木国夫.

${ }^{3} \mathrm{bp}, 60^{\circ}$ 
stirring. The resulting mixture was heated at $80^{\circ}$ for $15 \mathrm{~min}$, and the precipitate formed was removed by centrifugation. The supernatant was saturated with ammonium sulfate and flavin compounds in the solution were extracted with phenol and transferred to water by shaking with a mixture of ethyl ether and petroleum ether ${ }^{3}(1: 2, \mathrm{v} / \mathrm{v})$. Extracted material was separated on a TLC plate (silica gel-alumina, $1: 2, \mathrm{w} / \mathrm{w})$ using $\mathrm{CHCl}_{3}$-methanolacetic acid $(80: 20: 1, \mathrm{v} / \mathrm{v} / \mathrm{v})$ as a developer. A typical TLC pattern of the extract from rabbit portal blood is shown in Fig. 1. There are obviously two distinct yellow fluorescent spots on the plate when exposed to mineral light in the dark place. The $R f$ values of these spots are clearly different from the $R f$ value of free riboflavin, but the $R f$ value of the most rapidly moving band is identical with that of authentic $\mathrm{B}_{2}$-Nic. In addition, such components could not be detected in the extract of portal blood from the control rabbit. Hence, it is reasonable to consider that the component having larger $R f$ value is $\mathrm{B}_{2}-\mathrm{Nic}$, and the component of smaller $R f$ value may be its partial hydrolysate.

Although at present the quantitative evaluation is lacking, this simple result would be direct evidence for the incorporation of orally administered $\mathrm{B}_{2}$-Nic into the blood stream of animal body without losing the intactness of the ester bonds. Certainly, free riboflavin and nicotinic acid liberated from $\mathrm{B}_{2}$ $\mathrm{Nic}$ in the gastro-intestinal tract should also be incorporated, but it would be extremely difficult to consider that they can recombine with each other to produce $\mathrm{B}_{2}-\mathrm{Nic}$ after being incorporated into the animal body.

Kotaki et al. (4) have recently found that the increase of lipoperoxides in the liver of rat suffering from fatty liver is prevented when rats are fed on $\mathrm{B}_{2}$ - Nic containing diet, whereas no prevention was observed when rats are fed on riboflavin containing diet. The result would now be well-explained by the direct lipoperoxide-reducing action of the isoalloxazine part of $\mathrm{B}_{2}-\mathrm{Nic}$ which would reach the liver without losing its lipophilic and deposit-type nature.

\section{REFERENCES}

1. Kotaki, A., and Yagi, K., J. Vitaminol., 14, 247 (1968).

2. Yagi, K., Okuda, J., Dmitrovskii, A. A., Honda, R., and Matsubara, T., J. Vitaminol., 7, 276 (1961).

3. Tanaka, T., Tanaka, H., and Tsubaki, T., Vita. mins, 38, 229 (1968).

4. Kotaki, A., Okumura, M., Nakagawa, Y., and Yagi, K., J. Vitaminol., 15, 43 (1969). 